\title{
Primary Non-adherence to Prescribed Medications
}

\author{
Michael A. Fischer, MD, MS, Margaret R. Stedman, PhD, Joyce Lii, MS, MA, Christine Vogeli, PhD, \\ William H. Shrank, MD, MSHS, M. Alan Brookhart, PhD, and Joel S. Weissman, PhD
}

Brigham and Women's Hospital, Boston, MA, USA.

\begin{abstract}
Authors' Reply:- We agree with the comments of Karter and colleagues that our methods could misclassify e-prescriptions as unfilled if they were paid for by sources other than the patient's insurance. As they note, there is no standard method for linking these types of data, although we hope that our analysis stimulates others to work on the development of such techniques. Karter and colleagues point out that their study found much lower rates of primary non-adherence than we did, ${ }^{1}$ although some of these differences may be due to differences between our study setting-community-based practices in the first year of a new e-prescribing initiativeand the study setting used by Karter et al.- established users of e-prescribing within the Kaiser system. The ability of a system like Kaiser to offer the convenience of retrieving a medication almost immediately, and at the same location as the doctor's office, could make it much easier for patients to fill their initial prescription. After that, however, adherence may drop off when patients need to come back to refill their prescriptions, as reflected in the finding described by Karter et al. Our study may also have found higher primary nonadherence if early experiences with the implementation of the e-prescribing system resulted in problems such as delays in the prescription reaching the pharmacy, which could lead more patients to abandon their prescriptions than would happen with a more established system.

At least two other recent studies of adherence to new prescriptions for diabetes and hypertension among patients treated in a single health system found non-adherence rates similar to those seen in our study. ${ }^{2,3}$ As with the comparison between our findings and those of Karter et al., it is difficult to be certain whether these findings reflect some characteristics unique to the study setting as opposed to more universal
\end{abstract}

Published online May 7, 2010 behaviors around prescription filling. We agree that more such studies will be needed, both to improve the methods used for identifying primary non-adherence and to develop more robust estimates of the prevalence of this phenomenon in a wide variety of real-world practice settings.

The final comment by Karter and colleagues relates to the observations made by Lapane about how information on nonadherence can be used to improve care, especially in the context of e-prescribing use. Studies that can accurately identify patients who are non-adherent to their medications and that can further determine the optimum way to communicate this information to clinicians in order to facilitate intervention with patients will represent a major step towards better care for many chronic diseases.

Michael A. Fischer, MD, MS, Brigham and Women's Hospital, 1620 Tremont St, Boston, MA 02120, USA (e-mail: mfischer@partners.org).

\section{REFERENCES}

1. Karter AJ, Parker MM, Moffet HH, Ahmed AT, Schmittdiel JA, Selby JV. New prescription medication gaps: a comprehensive measure of adherence to new prescriptions. Health Serv Res. 2009;44:1640-61.

2. Shah NR, Hirsch AG, Zacker C, Taylor S, Wood GC, Stewart W. Factors associated with first-fill adherence rates for diabetic medications: a cohort study. J Gen Intern Med. 2009;24:233-7.

3. Shah NR, Hirsch AG, Zacker C, et al. Predictors of first-fill adherence for patients with hypertension. Am J Hypertens. 2009;22:392-6.

$\mathrm{J}$ Gen Intern Med 25(8):765

DOI: $10.1007 / \mathrm{s} 11606-010-1380-3$

(C) Society of General Internal Medicine 2010 